\title{
Taxing sugar-sweetened beverages: impact on overweight and obesity in Germany
}

\author{
Falk Schwendicke ${ }^{1 *}$ and Michael Stolpe ${ }^{2}$
}

\begin{abstract}
Background: Consumption of sugar-sweetened beverages (SSBs) increases the risk of overweight and obesity. Taxing SSBs could decrease daily energy consumption and body weight. This model-based study evaluated the impact of a 20\% SSB-sales tax on overweight and obesity in the context of Germany.

Methods: The population aged 15-79 years was modelled. Taxation was assumed to affect energy consumption via demand elasticities, which affected weight and BMI. Model-based analysis was performed to estimate the tax impact on BMl in different age, gender and income groups.

Results: Implementing a 20\% SSB tax reduced energy consumption mainly in younger age groups, males, and those with low income. Taxation decreased the mean BMI in younger groups, with the largest decrease in those aged 20-29 years, while effects in groups 60 years or above were minimal. In absolute terms, taxation was estimated to avoid 1,028,000 ( $-3 \%$ relative reduction) overweight individuals and 479,000 obese individuals $(-4 \%)$. Overweight decreased the most in males aged $20-29$ years $(408,000$ fewer cases $/-22 \%)$, the same applied for obesity $(204,000 /-22 \%)$.
\end{abstract}

Conclusions: An SSB tax could have significant impact on overweight and obesity, which could translate into substantial reductions of morbidity and mortality.

Keywords: Energy consumption, Health economics, Health policy, Obesity, Public health, Tax policy

\section{Background}

Overweight (defined as a body mass index of 25-29.9) and obesity (BMI $\geq 30$ ) are increasingly common, burdening billions of people around the world [1], while being associated with a large range of diseases spanning from cardiovascular (including hypertension and coronary heart disease) over endodocrinologic diseases (including diabetes mellitus type 2 and hyperlipidemia) to neoplasms and psychologic disorders $[2,3]$.

Sugar-sweetened beverages (SSBs) are an important dietary energy source. As they are freely available and actively marketed [4], their consumption has been increasing in many countries, contributing to the growing prevalence of obesity $[5,6]$. Given that the major SSB consumers are children, adolescents, and (often poorly educated) individuals from lower socio-economic status,

\footnotetext{
* Correspondence: falk.schwendicke@charite.de

'Department of Operative and Preventive Dentistry, Charité -

Universitätsmedizin Berlin, Aßmannshauser Str. 4-6, 14197 Berlin, Germany

Full list of author information is available at the end of the article
}

who are less aware of SSBs' harmful effects, there have been calls calling for governmental action to act to reduce SSB consumption [7].

An SSB tax has been suggested to restrict SSB consumption. Given the consumption profile, such tax would likely reduce SSB and energy consumption and associated morbidities mainly in low- instead of high-income groups, thereby alleviating existing inequities in health [8-10]. The revenues of the tax could be further used for further public health actions against overweight and obesity, like subsidizing healthy drinks or foods [4]. SSB taxes are in place in several US states, Mexico and a number of European and Pacific countries [7, 11], and have been found effective for reducing SSB consumption in natural experiments $[12,13]$.

A number of health economic modeling studies found an SSB tax to reduce the risk of overweight and obesity $[4,14-18]$. At present, no evidence on how this tax 
would reduce overweight and obesity in Germany are available. The present study aimed to provide such evidence.

\section{Methods}

\section{Overview}

This modelling study was built on the rationale that price increases as a consequence of additional SSB taxation would change SSB and other beverage purchases. The basis for our predictions as to this purchase reaction were empirical price elasticities of demand. Changed purchases resulted in altered energy consumption and, eventually, impacted on an individual's weight, thereby changing the BMI. We further assumed that beverage consumption and weight/BMI differed according to gender, age and income groups in the II German Nutrition Survey (NSV II). Elasticities were also assumed to differ between income groups. The model underlying this study (Fig. 1) has been previously used to estimate the impact of an SSB tax on dental caries and to estimate potential revenues as well as cost

\section{$\operatorname{Tax}$}

Elasticity data from
recent meta-analysis (17)

\section{Elasticity}

Consumption data from

Nutritional Survey NSV II (21)

\section{Beverage consumption}

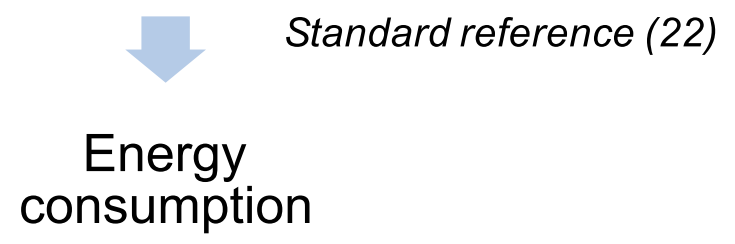

\section{Linear reduction: $1 \mathrm{~kg}$ per $94 \mathrm{~kJ}(18,31)$}

\section{Weight and $\mathrm{BMI}$}

Fig. 1 The SSB tax was assumed to affect consumption of different beverages via elasticity of demand, which in turn affected energy consumption and, consequently, body weight and BMI. The references for different data sources are additionally shown savings from such a tax in the context of German healthcare [19].

\section{Comparators}

Theoretically, an SSB tax can be levied per calorie value or gram of sugar ("specific tax"), or per value of sales unit ("ad valorem tax"), and can be implemented as an excise tax (before sales) or as a sales tax (at point of sale). We modelled the implementation of a national $20 \%$ sales tax on SSBs as an addition to existing value added tax (VAT). In our study, SSBs were beverages with added caloric sugars such as lemonades, fruit or sport drinks, but not fruit juice, milk products, non-sweetened (tea or coffee) or artificially sweetened beverages. The comparator was current practice, i.e. 0\% SSB tax.

\section{Setting and perspective}

The setting of this study was Germany. As we did not assess any cost of disease impact or tax revenues, no further specifications of the perspective of this study needed to be made.

\section{Target population and horizon}

We simulated the 2015 German population aged 15-79 years. Those aged 14 years or younger were not investigated because consumption data were unavailable, while those aged $>79$ years were excluded because their SSB consumption was negligible. Modeling was stratified by sex and in 10-year age bands (except for 15-19 years). Population data were drawn from 2012 federal statistics, assuming no changes since then [20]. Household income data were used to construct three income strata, assuming that income was associated with beverage consumption and obesity (as reported in the II German Nutrition Survey, NSV II) as well as own- and cross-price elasticities (using additional data from a recent meta-analysis [17]). As we assumed any changes in energy intake to result in steady state weight changes (see below), we did not need to follow-up patients (i.e. the horizon of this study was a few months until this steady state of weight was reached). Note that this also assumes our price-elasticities explain short-term changes in demand; in the longer term, price elasticities tend to be higher and the effect of the SSB tax on obesity would likely be even larger.

\section{Beverage and energy consumption}

Details on beverage and energy consumption can be found elsewhere [19]. Briefly, estimates of beverage consumption (specifically, SSB, fruit juice, milk) in different gender, age and income groups from the NSV II [21] were matched with population age groups. While the overall volume of consumed beverages was known, the specific consumption of each beverage type was reported 
only by gender and income. We assumed that relative differences between gender and income groups as to the share of different consumed beverage types per overall volume were constant across age groups, too. This approach was validated by comparing the expected overall consumptions with the summed consumptions of different beverage types in all groups (Table 1). Beverage consumption was transformed into energy consumption via energy density (Table 2) using a Standard Reference [22].

\section{Effectiveness}

Our health outcome parameter was the BMI, i.e. an individual's weight in $\mathrm{kg}$ per squared body height in meters. Implementation of an SSB tax was assumed to change energy consumption and, thereby, weight. As body height was stable, BMI changed.

\section{Price elasticity and pass-on rate}

Price elasticity is consumers' relative increase or decrease in purchases of goods (here: beverages) in reaction to relative price changes (in this case resulting from taxation). Own-price elasticity is the percentage change in purchases of a good when the price of this good changes by one percent; cross-price elasticity is the percentage change in purchases of a good when the price of another good

Table 1 Consumption of SSBs, juice and milk (ml/day per capita) in different groups

\begin{tabular}{|c|c|c|c|c|c|c|c|}
\hline \multirow[b]{2}{*}{ Age } & & \multicolumn{3}{|c|}{$\begin{array}{l}\text { Male } \\
\text { Income groups }\end{array}$} & \multicolumn{3}{|c|}{$\begin{array}{l}\text { Female } \\
\text { Income groups }\end{array}$} \\
\hline & & low & middle & high & low & middle & high \\
\hline \multirow[t]{3}{*}{$15-18$} & SSB & 416 & 260 & 265 & 416 & 260 & 252 \\
\hline & Juice & 329 & 383 & 333 & 291 & 383 & 372 \\
\hline & Milk & 231 & 231 & 240 & 154 & 154 & 168 \\
\hline \multirow[t]{3}{*}{$19-24$} & SSB & 690 & 471 & 480 & 306 & 191 & 185 \\
\hline & Juice & 304 & 366 & 318 & 259 & 341 & 331 \\
\hline & Milk & 188 & 188 & 196 & 135 & 135 & 148 \\
\hline \multirow[t]{3}{*}{$35-34$} & SSB & 517 & 353 & 360 & 198 & 118 & 113 \\
\hline & Juice & 289 & 337 & 293 & 234 & 308 & 296 \\
\hline & Milk & 162 & 162 & 168 & 118 & 118 & 129 \\
\hline \multirow[t]{3}{*}{$35-50$} & SSB & 302 & 206 & 210 & 150 & 89 & 85 \\
\hline & Juice & 236 & 275 & 239 & 164 & 216 & 207 \\
\hline & Milk & 126 & 126 & 131 & 92 & 92 & 101 \\
\hline \multirow[t]{3}{*}{$35-50$} & SSB & 178 & 111 & 113 & 63 & 37 & 35 \\
\hline & Juice & 185 & 215 & 172 & 136 & 170 & 162 \\
\hline & Milk & 95 & 95 & 99 & 77 & 77 & 84 \\
\hline \multirow[t]{3}{*}{$65-80$} & SSB & 59 & 41 & 41 & 41 & 24 & 23 \\
\hline & Juice & 124 & 143 & 114 & 139 & 174 & 165 \\
\hline & Milk & 85 & 85 & 88 & 83 & 83 & 91 \\
\hline
\end{tabular}

Note that consumption data for water etc. is not given changes by one percent. Since no elasticity data for Germany were obtainable, data reported in a recent meta-analysis [17] were used, details on this can be found elsewhere [19]. Briefly, own- and cross-price elasticities for SSBs (lemonade, fruit drinks), fruit juice and milk (average of whole and skim milk as far as this was assessed) were extracted. Elasticities differ by income status $[13,23]$, which is why we modelled elasticities in low and middle income groups separately from those in high income groups. Elasticities were assumed to not differ by age or gender (Table 2). As this assumption might lead to distortions via cross-price elasticities (specific age and gender groups who consume only minimal amounts of SSBs are likely to have a lower cross-price elasticity than high-SSB consuming groups), we additionally performed a sensitivity analysis, adjusting cross-elasticities in different age groups for the consumed amount of SSB. This was done by dividing the cross-price elasticities by the average SSB consumption over all age groups in a specific stratum (like male individuals with high income) and multiplying them with the estimated age-group specific SSB consumption, based on the plausible assumption that any consumer's cross-price elasticity would be zero in the limiting case of zero pre-tax SSB consumption (as there would be no post-tax reduction in SSB consumption to be substituted). That way, cross-price elasticities decreased in (mainly elderly) low SSB consuming groups and increased in (mainly young) high SSB consuming groups.

Manufacturers can pass a tax onto consumers as a price increase. Theoretically and assuming a fully competitive market, this pass-on rate should be $100 \%$, which we modelled in our base-case. However, many markets (the beverage market being one of them) are not fully competitive, with increased costs (as a result of the tax) being possibly absorbed by the manufacturer or even over-shifted to consumers [12, 24-28]. We therefore modelled an $80 \%$ pass-on rate in a sensitivity analysis.

\section{Impact on BMI}

To estimate the prevalence of overweight and obesity, data from the most recent national census was used [29], which builds on self-reported data for body weight and height in different sex, age, and income subgroups aged 18 years or above. For those aged 15-17, we used data from the German Study on Children and Adolescents [30]. Both body weight and height were modelled using the gamma function [31].

To estimate changes in BMI per changes in consumed energy, we used published energy balance equations [32], which had been used before for similar modelling studies, assuming that a daily reduction in energy intake of $94 \mathrm{~kJ}$ (SD: 2.96) would lead to a body weight reduction of $1 \mathrm{~kg}[18,31]$, with a new steady state body weight 
Table 2 Price-elasticities of demand and mean (min/max) energy content of different beverages

\begin{tabular}{|c|c|c|c|c|c|c|c|c|}
\hline \multirow[b]{3}{*}{ Beverage } & \multirow{2}{*}{\multicolumn{3}{|c|}{$\begin{array}{l}\text { Low or middle income stratum } \\
\text { Own-/Cross-price elasticity }\end{array}$}} & \multicolumn{3}{|c|}{ High income stratum } & \multirow[b]{3}{*}{ Source } & \multirow[t]{3}{*}{ Energy content (kcal/100 ml) } \\
\hline & & & & & & & & \\
\hline & Mean & 95\% lower $\mathrm{Cl}$ & $95 \%$ upper $\mathrm{Cl}$ & Mean & $95 \%$ lower $\mathrm{Cl}$ & 95\% upper Cl & & \\
\hline SSB & -1.21 & -3.87 & -0.69 & -0.908 & -2.903 & -0.518 & Long 2015 [17] & $42(37-50)$ \\
\hline juice & 0.637 & 0.140 & 1.447 & 0.459 & 0.098 & 1.0129 & Long 2015 [17] & $50(46-56)$ \\
\hline milk & 0.150 & -0.080 & 0.410 & 0.188 & -0.10 & 0.513 & Long 2015 [17] & $60(55-64)$ \\
\hline
\end{tabular}

Own price elasticity is highlighted in bold

Data from a recent meta-analysis [17] were used to estimate elasticities for SSBs (lemonade, fruit drinks), fruit juice and milk (average of whole and skim milk as far as this was assessed). Since elasticity differs by socio-economic (income) status [13, 23], we constructed two elasticity strata (low/middle and high income). Beverage consumption was transformed into energy consumption via energy density using a Standard Reference [22]

established thereafter [33]. We also assumed that the physical activity level of each individual would be unaffected by weight loss.

\section{Discount rate}

Discounting was not applied in this study given the short horizon.

\section{Analytical methods}

Spreadsheet-based Monte Carlo simulations were used to estimate the effect of an SSB tax on body weight and, subsequently, BMI. Parameter uncertainty was introduced by randomly sampling variables from triangular or gamma distributions. Note that parameters were drawn independently, ignoring a possible correlation. For each modeled group, 100 individuals were simulated, each group then being modeled 100 times. Computational constraints prevented a higher number of walks, which might have enhanced the reliability of results. Moreover, confidence intervals were only calculated for the primary analyses (changes in energy intake and $\mathrm{BMI}$ ), while for population level estimates, only point estimates were reported based on the sum of estimates yielded for separate groups [16]. Microsoft Excel (Microsoft, Redwood, USA), YASAIw (University of Washington) and SPSS 20 (IBM, Armonk, USA) were used for modeling and analysis.

\section{Results}

Based on our simulations, a 20\% SSB tax reduced daily energy consumption in males and, to a lesser degree, females (Table 3). The reduction was higher in younger than older people, and in low- than in middle- or highincome individuals. In older individuals, especially females, taxation even increased energy consumption slightly. This was, as the assumed cross-price elasticity led to increased consumption of fruit juices (which have significant caloric value), while SSB consumption decreased only minimally (as absolute consumption was low in this age group even without taxation).

The mean BMI under current conditions was generally higher in male than female populations (except for those aged 15-19 years), and increased with age up to the age group 60-69 years. BMI was also inversely associated with income. Most individuals aged 30 or above were overweight according to the mean BMI (Table 4). Assuming implementation of an SSB tax, the BMI decreased mainly in younger groups, with the largest decrease in those aged 20-29 years (Table 4). Taxation also decreased the BMI in groups with low rather than high income, and males rather than females. Taxation had no or even minimally disadvantageous effect on $\mathrm{BMI}$ in groups 60 years or above (given the described increased consumption of fruit juice).

On the population level, taxation avoided 1,028,000 $(-3 \%)$ overweight individuals and 479,000 (-4\%) obese

Table 3 Mean (SD) change of daily energy consumption (kJ/capita) at 20\% SSB tax

\begin{tabular}{|c|c|c|c|c|c|c|}
\hline \multirow{2}{*}{$\begin{array}{l}\text { Age group } \\
\text { (years) }\end{array}$} & \multicolumn{3}{|c|}{ Male income groups } & \multicolumn{3}{|c|}{ Female income groups } \\
\hline & Low & Middle & High & Low & Middle & High \\
\hline $15-19$ & $-166(125)$ & $-65(93)$ & $-34(66)$ & $-172(120)$ & $-68(87)$ & $-45(59)$ \\
\hline $20-29$ & $-376(179)$ & $-210(140)$ & $-159(99)$ & $-128(81)$ & $-22(63)$ & $-15(41)$ \\
\hline $30-39$ & $-251(126)$ & $-134(99)$ & $-119(80)$ & $-55(59)$ & $-5(47)$ & $14(36)$ \\
\hline $40-49$ & $-129(83)$ & $-69(65)$ & $-54(48)$ & $-52(459$ & $5(38)$ & $5(25)$ \\
\hline $50-59$ & $-61(55)$ & $-9(38)$ & $-15(28)$ & $8(26)$ & $23(25)$ & $21(15)$ \\
\hline $60-69$ & $5(20)$ & $20(20)$ & $11(14)$ & $18(20)$ & $39(22)$ & $33(17)$ \\
\hline $70-79$ & $4(21)$ & $21(20)$ & $11(26)$ & $19(24)$ & $38(21)$ & $31(16)$ \\
\hline
\end{tabular}

Different gender, age and income groups were modelled. Note that in some groups, an SSB tax increased energy consumption, as SSB consumption was minimal even without taxation, but cross-elasticity increased consumption of juice, resulting in higher energy consumption 
Table 4 Mean (SD) BMl of different gender, age and income groups with and without implementation of an SSB tax

\begin{tabular}{|c|c|c|c|c|c|c|c|}
\hline \multirow{2}{*}{$\begin{array}{l}\text { Age group } \\
\text { (years) }\end{array}$} & & \multicolumn{3}{|c|}{ Male income groups } & \multicolumn{3}{|c|}{ Female income groups } \\
\hline & & Low & Middle & High & Low & Middle & High \\
\hline \multirow[t]{2}{*}{$15-19$} & No tax & $24.0(4.2)$ & $21.7(2.9)$ & $21.9(3.2)$ & $24.8(4.4)$ & $23.7(3.3)$ & $20.4(3.5)$ \\
\hline & Tax & $23.3(3.9)$ & $21.5(3.1)$ & $21.7(3.3)$ & $24.0(3.9)$ & $23.4(3.2)$ & $20.2(3.5)$ \\
\hline \multirow[t]{2}{*}{$20-29$} & No tax & $25.2(3.2)$ & $24.8(3.9)$ & $23.6(3.8)$ & $21.4(3.2)$ & $22.5(3.9)$ & $21.4(4.1)$ \\
\hline & Tax & $23.9(3.3)$ & $24.1(3.3)$ & $23.1(3.5)$ & $21.3(3.3)$ & $22.5(4.2)$ & $21.4(4.1)$ \\
\hline \multirow[t]{2}{*}{$30-39$} & No tax & $27.8(6.1)$ & $25.4(4.3)$ & $25.8(4.9)$ & $26.2(4.3)$ & $23.5(4.9)$ & $21.8(5.1)$ \\
\hline & Tax & $26.9(5.4)$ & $24.9(2.9)$ & $25.4(4.3)$ & $26.0(4.2)$ & $23.5(5.5)$ & $21.8(5.1)$ \\
\hline \multirow[t]{2}{*}{$40-49$} & No tax & $28.3(5.4)$ & $26.9(6.3)$ & $27.2(5.6)$ & $25.7(3.9)$ & $24.7(5.1)$ & $22.6(4.6)$ \\
\hline & Tax & $27.8(5.8)$ & $26.8(5.7)$ & $27.0(5.5)$ & $25.6(3.6)$ & $24.7(5.3)$ & $22.6(4.6)$ \\
\hline \multirow[t]{2}{*}{$50-59$} & No tax & $29.1(5.1$ & $27.6(5.2)$ & $27.0(5.3)$ & $27.6(6.2)$ & $25.2(6.1)$ & $23.8(5.1)$ \\
\hline & Tax & $28.9(5.9)$ & $27.6(6.1)$ & $27.0(4.9)$ & $27.5(6.4)$ & $25.3(6.2)$ & $23.7(4.9)$ \\
\hline \multirow[t]{2}{*}{$60-69$} & No tax & $28.6(6.1)$ & $27.8(5.8)$ & $27.6(6.1)$ & $29.6(6.8)$ & $26.1(5.9)$ & $25.1(4.7)$ \\
\hline & Tax & $28.6(5.7)$ & $27.9(5.7)$ & $27.6(5.7)$ & $29.7(6.6)$ & $26.2(5.7)$ & $25.2(5.0)$ \\
\hline \multirow[t]{2}{*}{ 70-79 } & No tax & $28.2(5.5)$ & $26.3(6.0)$ & $25.9(4.3)$ & $30.0(7.1)$ & $26.0(5.0)$ & $25.2(5.4)$ \\
\hline & Tax & $28.2(6.0)$ & $26.3(6.1)$ & $26.0(4.2)$ & $30.1(7.0)$ & $26.1(5.5)$ & $25.3(5.5)$ \\
\hline
\end{tabular}

Note that in few groups, assumed cross-elasticity led to increased consumption of juice, while SSB consumption was low anyway; this led to higher BMI if a tax was implemented

individuals. The benefit of a tax for reducing the prevalence of overweight and obesity was largest in those aged 20-29 years and male groups (Table 5). Obesity was also reduced mainly in male populations. Translating these relative changes in the prevalence rates to absolute numbers of avoided cases of overweight and obesity (Table 6) shows that the largest benefit would, again, occur in younger and mainly male groups.

Table 5 The relative difference in prevalence rates (in \%) of overweight and obesity when levying a 20\% SSB tax compared with no tax, in different gender, age and income groups

\begin{tabular}{|c|c|c|c|c|c|c|c|}
\hline \multirow{2}{*}{$\begin{array}{l}\text { Age group } \\
\text { (years) }\end{array}$} & & \multicolumn{3}{|c|}{ Male income groups } & \multicolumn{3}{|c|}{ Female income groups } \\
\hline & & Low & Middle & High & Low & Middle & High \\
\hline \multirow[t]{2}{*}{$15-19$} & Overweight & -13 & -9 & -8 & -12 & -9 & -7 \\
\hline & Obese & -16 & -12 & 0 & -16 & -11 & 0 \\
\hline \multirow[t]{2}{*}{$20-29$} & Overweight & -28 & -20 & -20 & -20 & -7 & -5 \\
\hline & Obese & -44 & -28 & -4 & -12 & -4 & -3 \\
\hline \multirow[t]{2}{*}{$30-39$} & Overweight & -16 & -15 & -4 & -8 & 0 & +2 \\
\hline & Obese & -16 & -14 & -8 & -8 & +2 & +3 \\
\hline \multirow[t]{2}{*}{$40-49$} & Overweight & -4 & -4 & 0 & -8 & 0 & +2 \\
\hline & Obese & -4 & -2 & 0 & -4 & +2 & +3 \\
\hline \multirow[t]{2}{*}{$50-59$} & Overweight & 0 & 0 & 0 & 0 & +1 & +2 \\
\hline & Obese & 0 & 0 & 0 & 0 & +2 & +3 \\
\hline \multirow[t]{2}{*}{$60-69$} & Overweight & 0 & +1 & 0 & +1 & +2 & +3 \\
\hline & Obese & 0 & +1 & 0 & +2 & +2 & +2 \\
\hline \multirow[t]{2}{*}{ 70-79 } & Overweight & 0 & +1 & 0 & 0 & +2 & +5 \\
\hline & Obese & 0 & +1 & 0 & +2 & +4 & +7 \\
\hline
\end{tabular}

Surprisingly, taxation had no benefit at the population level in most female groups with middle or high income and, generally, in groups aged 60 years or above. Within the applied model, mean energy consumption even increased in these groups (compare with Table 3). That was as absolute consumption levels of SSBs, milk and juice differed markedly in the older compared with younger

Table 6 Avoided number of overweight or obese individuals (in thousand) per different gender, age and income groups

\begin{tabular}{|c|c|c|c|c|c|c|c|c|}
\hline \multirow{2}{*}{$\begin{array}{l}\text { Age } \\
\text { group } \\
\text { (years) }\end{array}$} & & \multicolumn{3}{|c|}{$\begin{array}{l}\text { Male income } \\
\text { groups }\end{array}$} & \multicolumn{3}{|c|}{$\begin{array}{l}\text { Female income } \\
\text { groups }\end{array}$} & \multirow[t]{2}{*}{ Totals } \\
\hline & & Low & Middle & High & Low & Middle & High & \\
\hline \multirow[t]{2}{*}{ 15-19 } & Overweight & 16 & 13 & 7 & 28 & 10 & 10 & 84 \\
\hline & Obese & 10 & 4 & 0 & 17 & 4 & 0 & 35 \\
\hline \multirow[t]{2}{*}{$20-29$} & Overweight & 140 & 132 & 136 & 80 & 14 & 13 & 515 \\
\hline & Obese & 108 & 80 & 16 & 28 & 6 & 6 & 244 \\
\hline \multirow[t]{2}{*}{ 30-39 } & Overweight & 108 & 120 & 15 & 44 & 0 & 0 & 287 \\
\hline & Obese & 56 & 60 & 11 & 20 & 0 & 0 & 147 \\
\hline \multirow[t]{2}{*}{ 40-49 } & Overweight & 36 & 44 & 0 & 60 & 0 & 0 & 140 \\
\hline & Obese & 16 & 16 & 0 & 20 & 0 & 0 & 52 \\
\hline \multirow[t]{2}{*}{ 50-59 } & Overweight & 2 & 0 & 0 & 0 & 0 & 0 & 2 \\
\hline & Obese & 1 & 0 & 0 & 0 & 0 & 0 & 1 \\
\hline \multirow[t]{2}{*}{ 60-69 } & Overweight & 0 & 0 & 0 & 0 & 0 & 0 & 0 \\
\hline & Obese & 0 & 0 & 0 & 0 & 0 & 0 & 0 \\
\hline \multirow[t]{2}{*}{ 70-79 } & Overweight & 0 & 0 & 0 & 0 & 0 & 0 & 0 \\
\hline & Obese & 0 & 0 & 0 & 0 & 0 & 0 & 0 \\
\hline \multirow[t]{2}{*}{ Totals } & Overweight & 302 & 309 & 158 & 212 & 24 & 23 & \\
\hline & Obese & 191 & 160 & 27 & 85 & 10 & 6 & \\
\hline
\end{tabular}


groups (absolute SSB consumption was very low among the elderly to begin with). Based on age-invariant crossprice elasticities that also did not allow the size of the elasticities to be contingent on initial consumption levels, the same exogenous price change due to a given SSB tax level led to a greater absolute increase in juice consumption among the elderly than their SSB consumption was decreased. Moreover, as both milk and juice were assumed to have higher energy densities than SSBs, this shift in absolute consumption was additionally aggravated when transformed into energy consumption. Last, older age groups generally consumed lower amounts of energy containing beverages (and instead more water), which reduces any impact of an SSB tax in this group.

As one reason for the net-increase in the elderly's energy consumption from taxation in Table 3 is the implausible invariance of cross-price elasticities with respect to age and initial SSB consumption levels, we additionally applied age-adjusted cross-price elasticities, based on the observation that the elderly have lower SSB consumption before tax and cross-price elasticities would be zero for any person with zero pre-tax SSB consumption, to evaluate the relative changes in the prevalence rates of overweight and obesity (Additional file 1: Table S1). It was notable that except for the age group 15-18 years, the reductions in prevalence were more homogenously distributed across age and income groups, with all groups benefiting from taxation, albeit in some groups at a lower level.

Compared with the base-case, assuming a lower passon rate reduced the absolute benefit of taxation (Table 7), as did decreasing the tax rate to $10 \%$ or $5 \%$. Applying age-adjusted cross-price elasticities had only limited impact on the overall absolute numbers of avoided overweight or obesity (Table 7).

\section{Discussion}

Based on this study, an SSB tax could decrease calorie consumption and average population BMI in Germany. Such findings are in line with observational studies confirming an effect of a tax on SSB purchases [12, 34].

Table 7 Scenario analyses

\begin{tabular}{lll}
\hline Scenario & $\begin{array}{l}\text { Number of avoided } \\
\text { overweight individuals } \\
\text { (thousand) }\end{array}$ & $\begin{array}{l}\text { Number of avoided } \\
\text { obese individuals } \\
\text { (thousand) }\end{array}$ \\
\hline Base-case & 1,028 & 479 \\
Pass-on 80\% & 718 & 280 \\
Tax 10\% & 465 & 164 \\
Tax 5\% & 276 & 50 \\
$\begin{array}{l}\text { Applying estimated age- } \\
\text { adjusted cross-price } \\
\text { elasticities }\end{array}$ & 976 & 449 \\
\hline
\end{tabular}

An SSB tax would be especially beneficial for younger individuals, males, and those with low income (i.e. the main SSB consumers), and could thus be valuable with regard to health equity, too [35]. Future studies should focus on this age group to assess benefits but also potential risks of an SSB tax. Overall and in absolute terms, one could expect a significant number of avoided overweight or obese individuals. The magnitude of the reduction both in relative and absolute terms is also similar to that reported for other countries, assuring us as to the validity of the used model [15-17]. However, when comparing estimated prevalence rates in different groups, we found certain under- and over-estimations in subgroups of income strata (especially for the prevalence for obesity), while the overall estimate (regardless of income groups) was near congruent with those found in epidemiologic surveys [30, 36].

Based on our findings, it is likely that the group to benefit the most are those aged 20-29 or, more generally, younger individuals, with higher benefits in male than female. This was mainly due to SSB consumption being high in these groups, while juice and milk consumption were low. It should be highlighted that, as discussed, it is uncertain if there would truly be an overall increase in energy consumption in elder and female groups, as our results in Table 3 suggest. Among the elderly, relatively stable behavioral patterns might have formed, which would mean that their own- and cross-price elasticities are lower than estimated for all age groups combined. Moreover, cross-price elasticities are likely to be lower at low initial levels of SSB consumption, as observed among the elderly. Applying different cross-price elasticities in low SSB consuming groups adjusted for the possible distortion and found the benefits of the tax to be more homogeneously distributed. However, as these age-specific estimates of elasticities were constructed on the basis of plausible behavioral assumptions instead of empirical evidence (to assess the robustness of our findings rather than to estimate precise effects), caution is needed when interpreting the findings of this sensitivity analysis.

This study has a number of strengths and limitations. First, nationally representative consumption data was used, which increases confidence in the policy implications. However, NSV II used dietary recording via diaries for estimating beverage consumption, which is prone for bias by misreporting. Further studies should strive and validate these consumption estimates using sales data. Data from NSV II could also be regarded as potentially outdated, as they were more than 7 years old; given the historic secular trend of an increasing consumption $[7,37]$ we could have under-estimated the effects of a tax on energy consumption and weight. Similarly, weight and height estimates were self-reported, with possible bias 
leading to underestimation of the BMI and possible underestimation of the benefits of a tax.

Second, elasticities were derived from a number of sources, as reported in a recent meta-analysis, and might not fully apply to Germany, leading to some distortions. Moreover, the used elasticity estimates are not agespecific and may thus lead to an over-estimation of the increase in juice consumption that an SSB tax triggers among the elderly, an issue which requires further study on the basis of age-specific elasticities. Ideally, one should also allow elasticity estimates to vary with initial SSB consumption levels (as attempted in our sensitivity analysis).

Third, the very concept of price elasticity of demand is an inevitable simplification based on the assumption that observed market demand is informative of individual behavioural responses to exogenous price changes, raising the issue of aggregation. Yet in research on tax policy, price elasticity is a well-established analytical tool to characterize (in one precise and easily compared summary measure) the shape of demand curves, i.e. plots of the geometric location of observed demand in a diagram with given prices of a good on the vertical axis and the quantities demanded at these prices on the horizontal axis, and to predict the empirical incidence of new taxes or tax changes. While in economic theory it is possible to specify downward-sloping demand curves by means of mathematical functions with constant price elasticity along the entire curve, the exact shape of real-world demand curves is usually unknown and could only be estimated with a very large number of individual observations. Their price elasticity is likely to vary with the initial level of demand before an exogenous price change, such as a tax, is introduced so that any elasticity estimate can only be an approximation for the relevant initial price level. An additional caveat is that price elasticities tend to ignore income effects of price changes, i.e. the reduction in available income for other goods after a purchase is made, but these effects are likely to be negligible in the present context as spending on SSBs is likely to be only a small proportion of consumers' total spending on consumption goods.

Fourth, substitution of SSBs with sugary foods has also not been modelled but might have some impact on energy consumption; there might even be a complementary relationship, implying an even larger benefit from taxing SSBs [38]. Fifth, the association between energy consumption and weight was assumed to be linear, leading to a new steady state after weight reduction occurred. This assumption is certainly a simplification, as different equations for men and women are likely to apply $[15,16,39]$. Metabolic rates might change after weight loss (for example due to different mobility of lighter than heavier individuals). Moreover, changes in energy intake due to elasticity might take place over a long-term period, which we did not account for. Similarly, we did not draw parameters from a correlation matrix, while weight, height and SSB consumption are likely to be correlated. Last, our study only describes the effects of a tax on obesity, while a range of other diseases may be triggered or aggravated. That, in turn, would also affect the cost-effectiveness. In general, it would be relevant to assess not only the effects of sugar consumption via increased energy intake, but also other proposed harmful effects of sugary diets [40].

\section{Conclusions}

Within these limitations and the specific assumptions made in this study, implementing a $20 \%$ tax on SSBs is likely to reduce overweight and obesity mainly in younger age groups, males and those with lower income. This finding, however, is highly dependent on estimates of the underlying own-price and cross-price elasticities, which might be improved through future research. In general, we expect significant relative and absolute benefits, which could translate into relevant effects on morbidity and mortality.

\section{Additional file}

Additional file 1: Table S1. Sensitivity analysis. The relative difference in prevalence of overweight and obesity rates when levying a 20\% SSB-tax compared with no tax, when applying age-adjusted cross-price elasticities (in \%). Compare with Table 5, where cross-price elasticities were not ageadjusted. (DOC $39 \mathrm{~kb}$ )

Abbreviations

BMI: Body mass index; SSB: Sugar sweetened beverages; VAT: Value added tax

Acknowledgements

Not applicable.

Funding

This study was funded by the authors and their institutions. The authors deny any conflict of interest.

Availability of data and materials

All data is available in this manuscript.

Authors' contributions

FS conceived and designed the study, constructed the model, performed the analysis, interpreted the data, wrote and approved the manuscript. MS designed the study, validated the model, interpreted the data, critically revised and approved the manuscript.

Competing interests

The authors declare that they have no competing interests.

Consent for publication

Not applicable.

Ethics approval and consent to participate

Not applicable. 


\section{Author details}

Department of Operative and Preventive Dentistry, Charité -

Universitätsmedizin Berlin, Aßmannshauser Str. 4-6, 14197 Berlin, Germany.

${ }^{2}$ Kiel Institute for the World Economy, Kiellinie 66, 24105 Kiel, Germany.

\section{Received: 6 July 2016 Accepted: 13 December 2016}

Published online: 17 January 2017

\section{References}

1. Ng M, Fleming T, Robinson M, Thomson B, Graetz N, Margono C, Mullany EC, Biryukov S, Abbafati C, Abera SF, et al. Global, regional, and national prevalence of overweight and obesity in children and adults during 19802013: a systematic analysis for the Global Burden of Disease Study 2013. Lancet. 2014;384(9945):766-81.

2. Visscher TL, Seidell JC. The public health impact of obesity. Annu Rev Public Health. 2001;22:355-75

3. Konnopka A, Bodemann M, Konig HH. Health burden and costs of obesity and overweight in Germany. Eur J Health Econ. 2011;12(4):345-52.

4. Cabrera Escobar MA, Veerman JL, Tollman SM, Bertram MY, Hofman KJ. Evidence that a tax on sugar sweetened beverages reduces the obesity rate: a meta-analysis. BMC Public Health. 2013;13:1072.

5. Hu FB. Resolved: there is sufficient scientific evidence that decreasing sugarsweetened beverage consumption will reduce the prevalence of obesity and obesity-related diseases. Obes Rev. 2013;14(8):606-19.

6. Malik VS, Popkin BM, Bray GA, Despres JP, Hu FB. Sugar-sweetened beverages, obesity, type 2 diabetes mellitus, and cardiovascular disease risk. Circulation. 2010;121(11):1356-64

7. Brownell KD, Farley T, Willett WC, Popkin BM, Chaloupka FJ, Thompson JW, Ludwig DS. The public health and economic benefits of taxing sugarsweetened beverages. N Engl J Med. 2009:361(16):1599-605.

8. Eyles $\mathrm{H}, \mathrm{Ni}$ Mhurchu C, Nghiem N, Blakely T. Food pricing strategies, population diets, and non-communicable disease: a systematic review of simulation studies. PLoS Med. 2012;9(12):e1001353.

9. Powell LM, Chaloupka FJ. Food prices and obesity: evidence and policy implications for taxes and subsidies. Milbank Q. 2009;87(1):229-57.

10. Powell LM, Chriqui JF, Khan T, Wada R, Chaloupka FJ. Assessing the potential effectiveness of food and beverage taxes and subsidies for improving public health: a systematic review of prices, demand and body weight outcomes. Obes Rev. 2013;14(2):110-28.

11. Chriqui JF, Chaloupka FJ, Powell LM, Eidson SS. A typology of beverage taxation: multiple approaches for obesity prevention and obesity preventionrelated revenue generation. J Public Health Policy. 2013;34(3):403-23.

12. Colchero MA, Popkin BM, Rivera JA, Ng SW. Beverage purchases from stores in Mexico under the excise tax on sugar sweetened beverages: observational study. BMJ. 2016;352:h6704.

13. Colchero MA, Salgado JC, Unar-Munguia M, Hernandez-Avila M, RiveraDommarco JA. Price elasticity of the demand for sugar sweetened beverages and soft drinks in Mexico. Econ Hum Biol. 2015;19:129-37.

14. Basu S, Vellakkal S, Agrawal S, Stuckler D, Popkin B, Ebrahim S. Averting obesity and type 2 diabetes in India through sugar-sweetened beverage taxation: an economic-epidemiologic modeling study. PLoS Med. 2014;11(1): e1001582.

15. Briggs AD, Mytton OT, Kehlbacher A, Tiffin R, Rayner M, Scarborough P. Overall and income specific effect on prevalence of overweight and obesity of $20 \%$ sugar sweetened drink tax in UK: econometric and comparative risk assessment modelling study. BMJ. 2013;347:f6189.

16. Briggs AD, Mytton OT, Madden D, O'Shea D, Rayner M, Scarborough P. The potential impact on obesity of a 10\% tax on sugar-sweetened beverages in Ireland, an effect assessment modelling study. BMC Public Health. 2013;13:860.

17. Long MW, Gortmaker SL, Ward ZJ, Resch SC, Moodie ML, Sacks G, Swinburn BA, Carter RC, Claire Wang Y. Cost Effectiveness of a Sugar-Sweetened Beverage Excise Tax in the U.S. Am J Prev Med. 2015;49(1):112-23.

18. Manyema M, Veerman L, Chola L, Tugendhaft A, Sartorius B, Labadarios D, Hofman KJ. The potential impact of a $20 \%$ tax on sugar-sweetened beverages on obesity in South African adults: a mathematical model. PLoS One. 2014:9(8):e105287.

19. Schwendicke F, Thomson W, Broadbent JM, Stolpe M. Taxing sugarsweetened beverages: effects on caries and treatment costs. J Dent Res. 2016;95(12):1327-32.

20. Online-Datenbank. Fortschreibung des Bevölkerungsstandes (Stand: 31.05.2012)

21. Nationale Verzehrsstudie II. Teil 2
22. National Nutrient Database for Standard Reference Release 28

23. Colchero MA, Salgado JC, Unar-Munguia M, Molina M, Ng S, RiveraDommarco JA. Changes in prices after an excise tax to sweetened sugar beverages was implemented in Mexico: evidence from urban areas. PLoS One. 2015;10(12):e0144408.

24. Bonnet $C$, Réquillart $\mathrm{V}$. Tax incidence with strategic firms in the soft drink market. J Public Econ. 2013;106:77-88.

25. Berardi N, Sevestere P, Tepaut M, Vigneron A. The impact of a 'soda tax' on prices: evidence from French micro data. In: Banque de France working paper No 415. Paris: Banque de France; 2012.

26. Besley T, Rosen H. Sales taxes and prices: an empirical analysis. Natl Tax J. 1999;52(2):157-78.

27. Bahl R. The uneasy case against discriminatory excise taxation: soft drink taxes in Ireland. Public Finance Review. 2003;31(5):510-33.

28. Falbe J, Rojas N, Grummon AH, Madsen KA. Higher retail prices of sugarsweetened beverages 3 months after implementation of an excise tax in Berkeley. California Am J Public Health. 2015;105(11):2194-201.

29. Mikrozensus 2013, https://www.destatis.de/.

30. Studie zur Gesundheit von Kindern und Jugendlichen in Deutschland (KiGGS)

31. Manyema M, Veerman JL, Chola L, Tugendhaft A, Labadarios D, Hofman K. Decreasing the burden of type 2 diabetes in South Africa: the impact of taxing sugar-sweetened beverages. PLoS One. 2015;10(11):e0143050.

32. Swinburn BA, Sacks G, Lo SK, Westerterp KR, Rush EC, Rosenbaum M, Luke A, Schoeller DA, DeLany JP, Butte NF, et al. Estimating the changes in energy flux that characterize the rise in obesity prevalence. Am J Clin Nutr. 2009:89(6):1723-8

33. Christiansen E, Garby L. Prediction of body weight changes caused by changes in energy balance. Eur J Clin Investig. 2002;32(11):826-30.

34. Waterlander WE, Ni Mhurchu C, Steenhuis IHM. Effects of a price increase on purchases of sugar sweetened beverages. Results from a randomized controlled trial. Appetite. 2014;78:32-9.

35. Etilé F, Sharma A. Do high consumers of sugar-sweetened beverages respond differently to price changes? a finite mixture IV-tobit approach. Health Econ. 2015;24(9):1147-63.

36. Mensink GBM, Schienkiewitz A, Haftenberger M, Lampert L, Ziese T, ScheidtNave C. Übergewicht und Adipositas in Deutschland: Ergebnisse der Studie zur Gesundheit Erwachsener in Deutschland (DEGS1). Bundesgesundheitsblatt Gesundheitsforschung Gesundheitsschutz. 2013;56:786-94.

37. Otero G, Pechlaner G, Liberman G, Gürcan E. The neoliberal diet and inequality in the United States. Soc Sci Med. 2015;142:47-55.

38. Finkelstein EA, Zhen C, Bilger M, Nonnemaker J, Farooqui AM, Todd JE. Implications of a sugar-sweetened beverage (SSB) tax when substitutions to non-beverage items are considered. J Health Econ. 2013;32:219-39.

39. Scarborough $\mathrm{P}$, Morgan RD, Webster $\mathrm{P}$, Rayner M. Differences in coronary heart disease, stroke and cancer mortality rates between England, Wales, Scotland and Northern Ireland: the role of diet and nutrition. BMJ Open. 2011;1(1):e000263.

40. Lustig RH. Fructose: metabolic, hedonic, and societal parallels with ethanol. J Am Diet Assoc. 2010;110(9):1307-21.

\section{Submit your next manuscript to BioMed Central and we will help you at every step:}

- We accept pre-submission inquiries

- Our selector tool helps you to find the most relevant journal

- We provide round the clock customer support

- Convenient online submission

- Thorough peer review

- Inclusion in PubMed and all major indexing services

- Maximum visibility for your research

Submit your manuscript at www.biomedcentral.com/submit 